
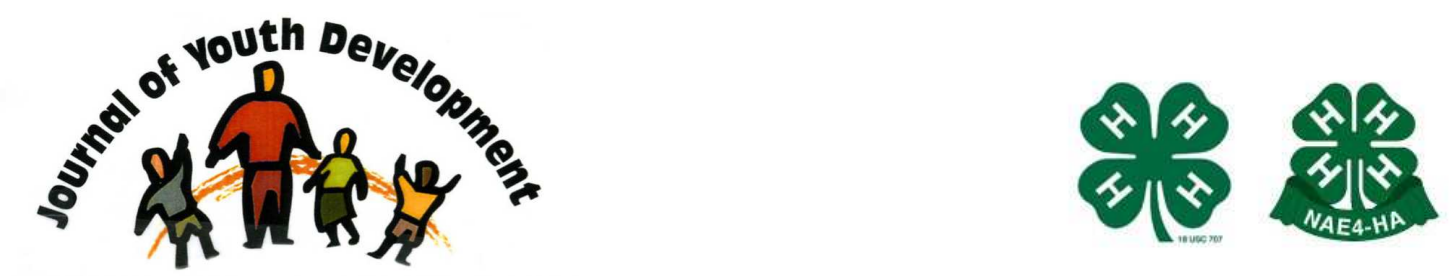

Bridging Research \& Practice

\title{
Feelings and Emotions in Youth's Purpose
}

\author{
Valeria Amorim Arantes \\ University of Sao Paulo \\ Sao Paulo, Brazil \\ varantes@usp.br \\ Viviane Potenze Guimarães Pinheiro \\ University of Sao Paulo \\ Sao Paulo, Brazil \\ vipinheiro@usp.br \\ Ulisses Ferreira Araujo \\ University of Sao Paulo \\ Sao Paulo, Brazil \\ uliarau@usp.br
}




\title{
JOURNAL OF YOUTH DEVELOPMENT \\ bridging research and practice

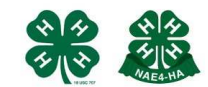

Volume 9, Number 4, Winter 2014

Article 140904RS001

\section{Feelings and Emotions in Youth's Purpose}

\begin{abstract}
Valeria Amorim Arantes, Viviane Potenze Guimarães Pinheiro and Ulisses Ferreira Araujo University of Sao Paulo, Brazil
\end{abstract}

\begin{abstract}
This article summarizes research that aimed to identify and analyze the Organizing Models of Thought - with its affective and cognitive dimensions - underlying the purpose of young Brazilians, and identifies possible relationships between values, feelings, emotions and purpose of 200 Brazilian High School students. Upon analyzing all the protocols, seven different ways of organizing thoughts were found when answering an open-ended questionnaire about purpose in life. It was observed that emotions and feelings play an important role in the construction of purpose for young people, exerting influence in organizing their thoughts and subsidizing their decisions, plans and justification for the actions.
\end{abstract}

\section{Introduction}

This article summarizes a study that aimed to identify and analyze the Organizing Models of Thought - including the affective and cognitive dimensions of thought - by examining possible relationships among the values, feelings, emotions and purpose of 200 Brazilian high school students. The question that drove this research was, "what role do feelings and emotions play in the development of youth purpose?"

This research complements another study, "Youth purpose and life goals of students engaged in community and social activities," which, similar to this study, was developed using a national sample and used the concept of purpose as developed by William Damon and his research group at the Stanford Center on Adolescence as a framework. Anchored in the principles of positive psychology, we understand that fostering the development of youth purpose can be a reliable tool that promotes resilience, motivation, optimism and self-esteem in adolescents and young adults.

According to Damon, Menon and Bronk (2003), purpose is a stable and generalized intention to accomplish something that is at once meaningful to the self and of intended consequence beyond the self. From this definition and based on the analysis of other authors (Bundick, 2009; Moran, 2009), we highlight three constituents of purpose: 
a) purpose always includes goals and objectives to be achieved over the long term that are characterized by a certain stability; a purpose can even change over time but should be stable enough to drive the subject to plan for present and future actions to achieve his/her goals;

b) purpose has an "external" orientation that transcends one's individuality; and

c) purpose should not be seen as a goal in itself but rather as a psychological strength that gives the subject a sense of direction, a goal to be achieved.

In short, purpose appears as a deeper reason that presents itself as a backdrop to the more immediate goals and motives and therefore purpose justifies the actions, concerns and choices of the individual (Damon, 2008).

A challenge faced by psychologists today is how to study the dynamics of psychological functions, while avoiding a simplified analysis of the complexity of the human mind. Attempting to make advancements in this area, we have adopted the organizing models of thought theory, which is anchored in Jean Piaget's theory and was developed by professors from the University of Barcelone and Geneve (Moreno, Sastre, Bovet, \& Leal, 1998).

The authors of the organizing models of thought theory promote a functional psychological system that synthesizes the results from diverse cognitive and affective activities, as revealed by subjects when evaluating specific situations. Among these activities, the following are outlined:

- Abstraction and selection of situational elements - When analyzing any phenomena, a subject selects part of the whole, taking some elements as significant and rejecting others that are considered to be not relevant. We highlight that a person can introduce abstraction process elements that are not present in the empirical phenomena that are observed, for example, through fantasy. In this mental process, feelings and emotions as well as previous personal experiences play an important role.

- Meaning given to elements considered to be relevant - Each subject gives meaning to each element abstracted from the phenomena. Thus, although the elements that are abstracted may be the same, they can have different meanings for different subjects who are analyzing the same situation.

- Relationships and/or implications established between the meaning given and the selected elements - Through inferences and implications established between all the elements abstracted and the meaning given, each subject psychologically organizes the situation and creates an organized model of thought.

In this way, the organizing models of thought are what each individual holds to be reality, out of which he/she elaborates patterns of conduct and explanations. They are based not only on the logic of human thought but also incorporate the desires, feelings, affects, social representations and values of the subject.

We understand, in our research, that this theory can be a powerful approach when investigating the psychological processes underlying the development of youth purpose. In this paper, we address our research question using the organizing models of thought theory as a procedural method. 


\section{Research and Method}

As previously discussed, our starting point is that purpose is an important psychological process that integrates feelings and values and plays a decisive role in a human being's sense of morality.

To study this assumption, we conducted a study with 200 young Brazilian students, 15- to 19years-old, from public high schools. In Brazil, public schools are attended mostly by people from lower socio-economic backgrounds. This non-probabilistic sample was representative of the five Brazilian geopolitical regions (South, Southeast, Midwest, North and Northeast) following the youth proportion in the overall population of each region according to the Brazilian Census defined by the Brazilian Institute of Geography and Statistics (IBGE).

In each region, the subjects lived in one of two types of municipalities, either a metropolis, characterized by a population of over $1,000,000$ inhabitants, or a regional capital, characterized by a population of approximately 250,000 inhabitants. Although gender was not a variable in the study, a balance between male and female was maintained in the sample.

Under the supervision of a researcher, subjects were invited to a computer lab to voluntarily answer an online open-ended questionnaire that was administered on the SurveyMonkey ${ }^{\circledR}$ platform. Based on the Youth Purpose Interview developed by William Damon, et al., (2003) at the Stanford Center on Adolescence, the instrument was composed of 13 questions regarding purpose and life goals, mediated by the role of feelings and emotions in the issues mentioned.

The instrument used in this research was:

\begin{tabular}{|c|c|c|}
\hline $\begin{array}{c}\text { Interview } \\
\text { development }\end{array}$ & Question & Goal \\
\hline Introduction & $\begin{array}{l}\text { 1) Tell me about yourself and your life, highlighting how } \\
\text { you feel about your life. }\end{array}$ & \\
\hline $\begin{array}{l}\text { Stage 1: } \\
\text { Self }\end{array}$ & $\begin{array}{l}\text { 2) What are the three most important things that you } \\
\text { care about? Please list them in order of importance }(X, Y \\
\text { and } Z) \text {, from the most important to the least important. } \\
\text { 3) How do you feel about each one of these? Explain in } \\
\text { detail. } \\
\text { 4) How did each of these things become important to } \\
\text { you? } \\
\text { 5) What are the obstacles you have faced regarding these } \\
\text { important things? }\end{array}$ & $\begin{array}{l}\text { Object } \\
\text { Feelings } \\
\text { Justification } \\
\text { Obstacles }\end{array}$ \\
\hline $\begin{array}{l}\text { Stage 2: } \\
\text { Changes / } \\
\text { stability }\end{array}$ & $\begin{array}{l}\text { 6) What would you want to be different in the world, and } \\
\text { how could you work towards making some of these } \\
\text { changes? } \\
\text { 7) How do you feel about that? }\end{array}$ & $\begin{array}{l}\text { Ideal world } \\
\text { Feelings }\end{array}$ \\
\hline $\begin{array}{l}\text { Stage 3: } \\
\text { Future } \\
\text { projections }\end{array}$ & $\begin{array}{l}\text { 8) Picture yourself } 5 \text { years from now and tell me what } \\
\text { you will be doing and what will be important to you? } \\
\text { 9) How will you feel } 5 \text { years from now? } \\
\text { 10) Now, picture yourself at } 40 \text { years old. What will you } \\
\text { be doing? Who will be in your life? What will be important } \\
\text { to you? } \\
\text { 11) How will you feel when you are } 40 \text { years old? }\end{array}$ & $\begin{array}{l}\text { Near future } \\
\text { Feelings } \\
\text { Distant future } \\
\text { Feelings }\end{array}$ \\
\hline $\begin{array}{l}\text { Stage 4: } \\
\text { Purpose }\end{array}$ & $\begin{array}{l}\text { 12) What does purpose (the concept) mean to you? } \\
\text { 13) If you have a purpose, how do you feel about it? }\end{array}$ & $\begin{array}{l}\text { Purpose } \\
\text { Feelings }\end{array}$ \\
\hline
\end{tabular}


Using this open-ended questionnaire, we gathered data that reflected the role that feelings and emotions play in judgments and representations of actions in purpose contexts, believing that thoughts, feelings and actions are part of a continuum in the function of the human psyche.

The analysis used in this research, based on the theoretical premises of the organizing models of thought theory, led us to apply the following method in a complex and long-term process:

a) read all the answers given in the questionnaire;

b) identify the central elements of each response extracted from the interview;

c) identify the meaning the subject gives to these elements (including the feelings they mention);

d) identify the implications the subjects give to the responses; and

e) identify the different organizing models the subjects use in the situation studied.

It is important to exemplify in this process that although the subjects may abstract the same elements from a situation (i.e., work and family in the youth purpose interview of this research), the elements may have different meanings and implications for different subjects. In other words, the subjects use different organizing models to explain "reality".

Furthermore, it is important to highlight that although each person is singular, there is no infinite model that analyzes every situation. However, as there are social and cultural patterns that influence the way human beings think about specific situations, we can find regularities in the organizing models of thought that the subjects used.

\section{Results}

We identified seven different ways people organized their thoughts when responding to the open-ended questions. We present a summary of these seven organizing models of thought, highlighting that there are some sub-models in which the meaning given to the central elements differ but are still composed of the same thought organization. In this article, we elected to focus on the models, while indicating the differences presented in some of the protocols.

\section{Organizing Model 1 - Fragile purposes}

Central organizing elements: labor and family

\section{Feelings related to Purpose: Well-being}

The central organizing elements, labor and family, were weakly related to well-being. The future was projected as an ordinary course of life. Participants did not involve their present actions in their purposes. Some participants mentioned, as central elements, "a negative experience in life" and "God". These elements contributed to a fragile vision of the future, suggesting the same meanings and implications as labor and family elements.

\section{Organizing Model 2 - Consumption and financial stability \\ Central organizing element: labor}

\section{Feelings related to purpose: Well-being, fulfillment, happiness and exhaustion}

Labor refers to the possibility of consumption and financial stability in the future and is related to feelings of well-being, fulfillment and happiness. Exhaustion is related to years of hard work. This study was developed in such a way as to be relevant to the labor market. 
Organizing Model 3 - Interpersonal relationships

Central organizing element: interpersonal relationships

Feelings related to purpose: Well-being, fulfillment, happiness and love

Interpersonal relationships are viewed in relation to three other elements: family, friends and labor. Future projections are related to good relationships and stability on the job. Love, happiness, fulfillment and satisfaction appear to be strongly related to the central elements, while happiness appears to be a projected value in the future.

Organizing Model 4 - Idealization of family and work

Central organizing elements: Labor and family

Feelings related to purpose: Well-being, fulfillment and happiness

Labor and family, in an idealized form, are related to well-being, fulfillment and happiness.

While these elements were strongly indicated as important by the subjects, they (the elements) did not engage the actions and involvement of the subjects nor were they elements that were projected for the future. Some participants emphasized God as a central element, suggesting this belief was a way to have a job in the church.

Organizing Model 5 - Labor and family

Central organizing elements: Labor and family

Feelings related to Purpose: Well-being, fulfillment, happiness, pride, gratitude and satisfaction

Work is a real goal for the subjects as it is required to support a family (responsibility). Labor and family were strongly related to well-being, fulfillment, happiness, pride, gratitude and satisfaction.

Organizing Model 6 - Labor

Central organizing element: Labor as a personal fulfillment Feelings related to purpose: Well-being, fulfillment, happiness and a sense of completeness

The subjects perceived labor as something that requires the personal effort of the subjects, and in turn, it provides them with pleasure, satisfaction, well-being and a sense of completeness. They also view labor as a way to contribute to society and way to gain social recognition and personal achievement.

\section{Organizing Model 7 - Beyond self}

Central organizing element: Help others through work and family responsibility Feelings related to purpose: happiness and fulfillment

There were a wide range of meanings given that provided both coherence and complexity to the responses. Labor was perceived as a way to achieve personal fulfillment and a way to obtain social recognition. Respondents, expressed gratitude for the education they had received when referencing family, and they expressed their desire to have a family and assume responsibility in the context of family. Respondents recognized the importance of their actions and involvement with respect to purpose. Feelings of fulfillment and happiness were related to the central elements, not only as experienced by the subject but also by the recipients of the actions. Some participants perceived labor in church as a way to contribute and express their altruism.

Figure 1 shows the distribution of the organizing models of thought applied by the 200 young subjects when answering the purpose questionnaire. 
Figure 1

General results: Distribution of Models

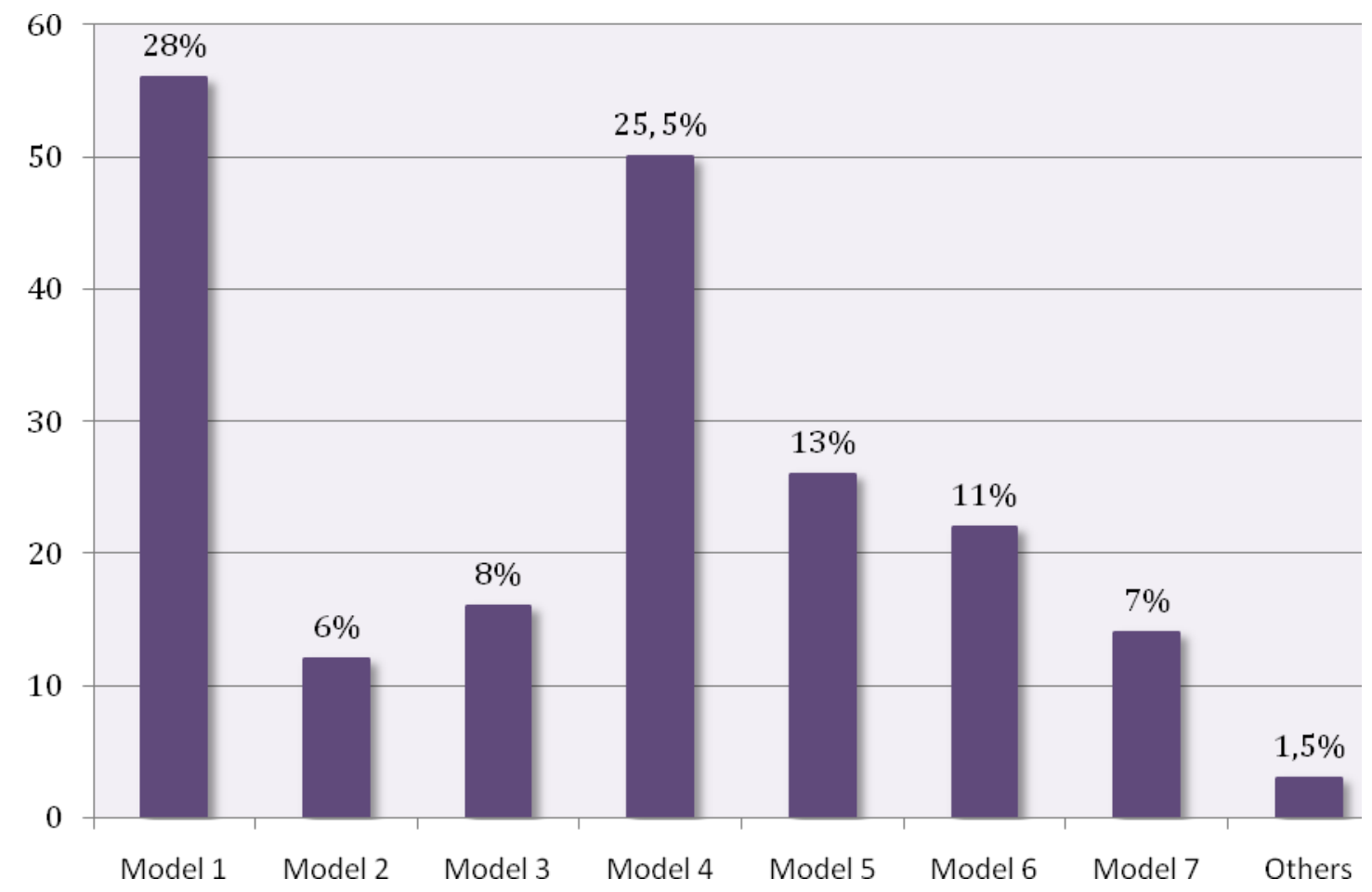

\section{Discussion}

In Model 1 , fragile projections about the future were evidenced, and no integration between feelings of well-being (when it appeared) and the abstract elements extracted from the responses (labor, family, God and religion) were apparent.

Therefore, if in Model 1 there was no integration of values and feelings, in Model 2 there was an integration of the feelings of well-being, fulfillment and happiness with respect to the element of labor. This element was meant to be viewed by the participants as a consumption possibility and was a value that was important for receiving emotional satisfaction. Labor was also integrated with the feeling of tiredness/exhaustion when related to the years of effort and dedication that this value requires. This integration actually weakened the value placed on labor, as it added a negative aspect to it, suggesting that labor, as a value, was not of critical importance to these subjects.

Model 3 indicated that the central elements were those factors that are directly related to interpersonal relationships, such as happiness, which is integrated with feelings of well-being, fulfillment and love. The subjects who applied Model 3 argued that labor, family and friendships would provide happiness in the future. The integration between interpersonal relationships and happiness ensured the centrality of these values in the psychic organization of subjects by regulating the lack of importance given to other values and by being governed by feelings, especially of love, which although complex, aims at highlighting relationships and demonstrating the differences according to the links established (family, friendship, dating). 
While models 4, 5 and 6 revealed that labor and family were central elements. They also indicate that there were perceptible differences between these models and their respective submodels.

In Model 4, the elements labor and family were more structured and were regulated by feelings of well-being, fulfillment and happiness. Although there was such a regulation, it was clear that there was no integration of labor and family values as separate entities into an idealized form. In Model 4, some participants were quite emphatic in their references to God, as they expressed positive feelings about religion that were reflected in their organized reasoning. They further integrated this value into labor, leading the subjects to consider working for the church.

Contrary to Model 4, Model 5 showed a strong integration between labor and family, both of which were positively valued by young people. We understand that integration based on the observation that labor provides subjects an opportunity to bear responsibilities towards their family (help with expenses, financial support, etc.). This integration received a strong affective impetus, not only from feelings of well-being, fulfillment and happiness but also from feelings of pride, satisfaction and gratitude.

Despite focusing on only one value, labor, Model 6 is still highly complex. In Model 6, labor is presented as a personal achievement and means to attain social recognition, thereby yielding the positive emotional energy by promoting feelings of accomplishment, well-being and happiness.

Finally, in Model 7, with respect to the abstraction of the elements, the youths in this study identified a strong desire to reach others as their purpose. The complexity of this model is through the integration and regulation of values and feelings, as this model combined many of the values highlighted in the previous models, which promoted this complex integration. Labor and family values were integrated through the responsibility that the subject felt towards their family. Labor also integrated a desire to extend or go beyond labor. Accordingly, it is interesting to observe the regulation and integration of feelings in this sub-model, as they were understood by participants to refer to their own achievements with respect to work and family as well to the positive feelings experienced by the recipients of the actions.

The analysis of the integration and regulation of feelings and values conducted herein reflects the complexity that makes up the human psyche and the differences regarding the ways in which people process values and feelings with respect to purpose.

Despite using almost the same elements and feelings in all of the models, the dynamic of thought exhibited a greater integration than that of labor, family, and positive emotions, which was different in each model due to the complexity of the meanings given to each integration.

It is important to again mention that although God appeared to some participants as a central element, as an element, the contribution of God to purpose, as formulated by each participant, was perceived differently. In Model 1, some participants perceived God as an entity that would decide what was best for them. In Model 2, God was projected by some adolescents to represent an idealized form of labor in the church. In Model 3, some participants saw God as an entity who inspired them and gave meaning to their life in. In this model, the adolescents saw a direct relationship between church and labor in that church provided them a way to help others beyond that of simple volunteer work. The projection of positive feelings in each model was 
decisive with respect to its integration of values, thus resulting in different perspectives about the same element.

\section{Concluding Remarks}

From the results obtained through our investigation, we observed that emotions and feelings play an important role in the construction of purpose for young people. Accordingly, emotions and feelings influence how subjects organize their thoughts, make their decisions and plan and justify their actions.

Positive feelings deserve attention because they reinforce purpose and reflect how young subjects perceive their future selves. When these feelings were strongly integrated with their values, they guaranteed strength of purpose and likely helped subjects formulate more stable and generalized intentions.

Furthermore, the integration of values and feelings was fundamental to reasoning, thus leading participants to develop and formulate their purpose. When that integration did not occur, elements remained isolated and were not identified or were configured as being of central importance to the subjects (as in Model 1). This integration was also important in regulating the non-appearance of others reasoning forms, indicating that the integration of values and feeling plays a central role in organizing human thought, thereby contributing to youth engagement in establishing purpose.

It is important to note that $28 \%$ of the participants demonstrated fragile purposes. In others models, however, they demonstrated some amount of articulation between values and feelings, as there was evidence of a short list of meanings attributed to elements and feelings (excluding Models 6 and 7). These findings suggest the importance of working with young people in schools and at home and of facilitating their ability to reflect on their values and feelings.

The observed relationships between the construction of purpose and the configuration of emotions and feelings, as they pertain to reasoning, demonstrate the influence that the affective dimension plays in thought organization. This finding corroborates studies that emphasize the importance of affective aspects in psychological functioning and purpose, and it iterates the need to understand that purpose is constituted not only by cognitive and structural aspects that guide reasoning and development but also by other aspects, such as emotions and feelings.

\section{References}

Bundick, M.J. (2009). Pursuing the good life: An examination of purpose, meaningful engagement, and psychological well-being in emerging adulthood. Stanford Digital Repository. On-line: http://purl.stanford.edu/cb008zb6473.

Damon, W., Menon, J., Bronk, K.C. (2003). The Development of Purpose During Adolescence. Applied Developmental Science, 7 (3), 119-128.

Moran, S. (2009). Purpose: Giftedness in intrapersonal intelligence. High Ability Studies, 20 (2), 143-159. 
Moreno, M., Sastre, G., Bovet, M., Leal, A. (2008). Conocimiento y cambio: los modelos organizadores en la construcción del conocimiento [Knowledge and Change: the organizing models in knowledge's construction]. Barcelona: Paidos.

(C) Copyright of Journal of Youth Development $~$ Bridging Research and Practice. Content may not be copied or emailed to multiple sites or posted to a listserv without copyright holder's express written permission. Contact Editor at: patricia.dawson@oregonstate.edu for details. However, users may print, download or email articles for individual use.

ISSN 2325-4009 (Print); ISSN 2325-4017 (Online) 